\title{
Genetic Control of Fruit Sugar Accumulation in a Lycopersicon esculentum $\times$ L. hirsutum Cross
}

\author{
John R. Stommel ${ }^{1}$ and Kathleen G. Haynes \\ Vegetable Laboratory, Agricultural Research Service, U.S. Department of Agriculture, Beltsville, \\ MD 20705
}

Additional index words. reducing sugars, soluble solids concentration, sucrose, vegetable breeding

\begin{abstract}
Fruit of the cultivated tomato (Lycopersicon esculentum Mill.) store predominantly glucose and fructose whereas fruit of the wild species $L$. hirsutum Humb. \& Bonpl. characteristically accumulate sucrose. Reducing sugar and sucrose concentrations were measured in mature fruit of parental, $F_{1}, F_{2}$, and backcross $\left(B_{1}\right)$ populations derived from an initial cross of $L$. esculentum 'Floradade' $\times$ L. hirsutum PI 390514. Generational means analysis demonstrated that additive effects were equal to dominance effects for percentage of reducing sugar. It was determined that a single major gene, dominant for a high percentage of reducing sugar, regulates the percentage of reducing sugar in tomatoes. We propose that this gene be designated sucr. Only additive effects were demonstrated to be important for glucose : fructose ratios. Using $L$. hirsutum as a donor parent for increasing total soluble solids concentration in the cultivated tomato is discussed.
\end{abstract}

Sugars are an important component of tomato flavor and processing quality. Tomato flavor is a complex characteristic to measure and involves the perceived tastes and aromas of many chemical compounds. Stevens et al. (1977) determined that variation in sugar and acid concentration were significant contributors to genotypic flavor differences in tomato, with more intense flavor associated with high concentrations of these components. Since sugars comprise $55 \%$ to $65 \%$ of the total soluble solids (TSS) fraction and $\approx 50 \%$ of the total solids in tomatoes, they are also an important determinant of tomato processing quality. The amount of processed product that can be produced often depends directly on the solids concentration of the fruit. Considerable variability for TSS concentration is present within the cultivated tomato and its wild relatives. The TSS concentration of commercial cultivars generally ranges from $4.5 \%$ to $6.0 \%$ and can approach $15 \%$ in fruit of wild tomato species (Hewitt and Garvey, 1987).

Fruit of the cultivated tomato and those of red-fruited wild tomato species accumulate the reducing sugars glucose and fructose as the principal storage sugars during fruit development. Little or no sucrose is detectable in the mature fruit. In contrast, fruit of the green-fruited wild tomato species accumulate significant quantities of sucrose in addition to reducing sugars (Davies, 1966). Soluble sugars are osmotically active compounds and, hence, contribute significantly to the regulation of osmotic pressure and flow of water between cellular compartments in plant tissues. The reduced osmolarity present with equal amounts of sucrose and reducing sugars, when expressed on a glucose equivalent basis, contributes to enhanced sink strength in fruit that store sucrose. Ho (1979) demonstrated that the import of photosynthetic assimilate into tomatoes is determined by the sink strength of the individual fruit rather than the concurrent photosynthetic rate of the source leaf. Hewitt et al. (1982) examined two tomato genotypes differing in solids concentration and determined that fruit of the higher solids genotype were stronger assimilate sinks. In light of osmotic considerations, storage organs that accumulate high concentrations of soluble sugar generally favor sucrose accumulation

Received for publication 2 Nov. 1992. Accepted for publication 19 Mar. 1993. The cost of publishing this paper was defrayed in part by the payment of page charges. Under postal regulations, this paper therefore must be hereby marked advertisement solely to indicate this fact.

${ }^{1}$ To whom reprint requests should be addressed at USDA-ARS, Vegetable Lab., Bldg. 004, Rm. 220, BARC-West, 10300 Baltimore Ave., Beltsville, MD 20705.
(Giaquinta, 1979; Hatch et al., 1963; Steingrover, 1983; Stommel and Simon, 1989; Yelle et al., 1991). The consideration of osmotic potentials and sucrose storage in enhancing sugar accumulation and TSS concentrations in tomatoes is supported by the observations that the total quantity of soluble carbohydrate accumulated in fruit of many accessions of the sucrose-storing tomato speciesL. chmielewskii Rick, Kesickii, Fobes, Holle (Yelle et al., 1988), L. hirsutum (Miron and Schaffer, 1991), and L. peruvianum (L.) Mill. (Stommel, 1992)-is about twice that noted in L. esculentum, when expressed on a glucose equivalent basis.

Biochemical factors associated with sucrose accumulation in $L$. chmielewskii (Yelle et al., 1988), L. hirsutum (Miron and Schaffer, 1991), and L. peruvianum (Stommel, 1992) have been described. The genetic mechanisms controlling sucrose storage in tomatoes remain unclear. Yelle et al. (1991) suggested that one or two genes may control sucrose accumulation in L. chmielewskii fruit. However, significant deviation from the expected results, which may be attributed to close genetic linkage between genes that influence sucrose accumulation and sterility in their plant material, for a oneor two-gene model in that study prevent drawing definitive conclusions from those results. Nonsolanaceous plants in which genetic variation for storage-sugar type have been described include carrot (Daucus carota L.) (Freeman and Simon, 1983), muskmelon (Cucumis melo L.)(Hubbard et al., 1989), and pear (Pyrus communis L.) (Moriguchi et al., 1992). It was determined that a single gene regulates the reducing sugar : sucrose ratio in carrot roots, with dominance for a high percentage of reducing sugar (Freeman and Simon, 1983). Using populations derived from a cross of $L$. esculentum with the green-fruited sucrose accumulator, L. hirsutum, this report describes the genetic control of the percentage of reducing sugar in tomatoes.

\section{Materials and Methods}

Plant material. The populations used in this study were derived from two parental lines-L. esculentum 'Floradade' (female parent, $\mathrm{P}_{1}$ ) and L. hirsutum f. typicum PI 390514 (male parent, $\mathrm{P}_{2}$ ). Lycopersicon hirsutum seeds were obtained from the U.S. Dept. of Agriculture, Northeast Regional Plant Introduction Station, Geneva, N.Y. Plants were grown in the greenhouse to produce seeds of the $\mathrm{F}_{1}, \mathrm{~F}_{2}$, and backcross $\left(\mathrm{BC}_{1}\right)$ generations. Plants were grown in 5liter pots in a mixture of 6 steam-treated soil : 3 peat : 2 perlite (by volume), with regular applications of soluble fertilizer. The green- 
house day and night temperature cycle was maintained at a minimum of 21 and $16 \mathrm{C}$, respectively. Controlled crosses were made using standard emasculation and pollination methods to produce the $\mathrm{F}_{1}, \mathrm{~F}_{2}$, and $\mathrm{BC}_{1}$ generations. Lycopersicon esculentum 'Floradade', was used as the recurrent parent to produce the $\mathrm{BC}_{1}$ generation. Ripe fruit were collected for the analysis of sugar and TSS concentration from parental, $\mathrm{F}_{1}, \mathrm{~F}_{2}$, and $\mathrm{BC}_{1}$ plants grown under field conditions on sandy loam soils during Summer 1991 in Beltsville, Md.

Fruit sampling. At harvest, representative portions $\left(\mathrm{P}_{1}\right.$ and $\mathrm{BC}_{1}$, $\approx 5 \mathrm{~g} ; \mathrm{P}_{2}, \mathrm{~F}_{1}$ and $\mathrm{F}_{2}, \approx 1$ to $3 \mathrm{~g}$ ) of whole ripe fruit from each plant were frozen at $-20 \mathrm{C}$ to determine sugar concentration. For each plant, samples from three individual fruit were bulked before performing the sugar analysis. Three additional samples (L. esculentum, quartered fruit; L. hirsutum, whole fruit) were frozen at $20 \mathrm{C}$ for use in determining the percentage TSS concentration.

Sugar and TSS determinations. Tomato sugar analyses were performed as described previously (Stommel, 1992), with minor modifications. Samples were homogenized in a homogenizer (Kinematica; Brinkman Instruments, Westbury, N.Y.) at 4C in five parts distilled water containing $3 \%$ (by volume) saturated benzoic acid solution (to inhibit enzyme activity and microbial contamination). Homogenates were centrifuged at $20,000 \times g$ for 15 min at $4 \mathrm{C}$, and the supernatant was filtered using Whatman no. 2 filter paper. Filtered supernatants were eluted through a C18 Sep-Pakcartridge (Waters, Millford, Mass.) before filtration through a $0.45-\mu m$-membrane filter. Samples were held at $4 \mathrm{C}$ and sugars were quantified with high-performance liquid chromatography using a carbohydrate analysis column (Waters) and 75 acetonitrile : 25 water as the mobile phase $\left(2 \mathrm{ml} \cdot \mathrm{min}^{-1}\right.$ flow rate $)$ in conjunction with a refractometer (model 410; Waters).

TSS percentage was determined by crushing thawed fruit samples and measuring the refractive index of the expressed juice with a refractometer (Abbe model 32; Bausch and Lomb, Rochester, N.Y.).

Data were analyzed using Hayman's generational means analysis (Hayman, 1958, 1960). Due to unequal population sizes and heterogeneous variance between populations, the generational means were weighted by the reciprocal of the variance of the mean for each generation. When a population had a variance of zero, the variance was replaced by one.

\section{Results and Discussion}

Striking differences in sugar concentration were evident between the parent species used in this study (Table 1). Typical of the cultivated tomato, the L. esculentum parent, 'Floradade' $\left(\mathrm{P}_{1}\right)$, stored sugars in the form of reducing sugars. No sucrose was detectable in mature fruit of this cultivar. In contrast, fruit of $L$. hirsutum PI $390514\left(\mathrm{P}_{2}\right)$ contained predominantly sucrose, with reducing sugars comprising only $13 \%$ of the total sugars in mature fruit. These results are consistent with previous studies that have examined sugar accumulation during fruit development in wild and cultivated tomatoes (Davies and Kempton, 1975; Miron and Schaffer, 1991; Stommel, 1992; Yelle et al., 1988). The wild, green-fruited tomato species $L$. chmielewskii, L. hirsutum, and $L$. peruvianum characteristically accumulate high concentrations of sucrose during the latter phases of fruit development, with low concentrations of glucose and fructose present during the period. In L. esculentum, reducing-sugar concentration steadily increases during fruit development, with little or no detectable sucrose.

To characterize genetic components of storage-sugar type, $\mathrm{F}_{1}$, $\mathrm{F}_{2}$, and $\mathrm{BC}_{1}$ populations were developed from an initial cross of the parent $\left(\mathrm{P}_{1}\right)$ with a high percentage of reducing sugar $(L$. esculentum 'Floradade') and the parent $\left(\mathrm{P}_{2}\right)$ with a low percentage of reducing sugar (L. hirsutum PI 390514). Hayman's generational means analysis revealed that additive $(\mathrm{a}=43.11, \mathrm{SE}=1.77)$ and dominance $(\mathrm{d}=43.31, \mathrm{SE}=1.83)$ effects were about the same for percentage of reducing sugar. Fruit within respective $F_{1}, F_{2}$, and $\mathrm{BC}_{1}$ populations were categorized as containing a high or low percentage of reducing sugar, based on the percentage of reducing sugar characteristic of the parental lines (Fig. 1, Table 2). All fruit of the $20 \mathrm{~F}_{1}$ plants and $93 \mathrm{BC}_{1}$ plants from the backcross to the highreducing-sugar parent $\left(\mathrm{P}_{1}\right)$ contained a high percentage of reducing sugar, a result suggesting that additive and dominance effects were similar for percentage of reducing sugar. A good fit to an expected 3:1 ratio of tomatoes with a high to low percentage of reducing sugar was observed in $\mathrm{F}_{2}$ progeny $(P>0.1)$. These results suggest that a single major gene, dominant for a high percentage of reducing sugar, regulates this characteristic in tomatoes. Variation evident for percentage of reducing sugar in fruit of $\mathrm{P}_{2}$ and segregating $\mathrm{F}_{2}$ and $\mathrm{BC}_{1}$ populations suggests the presence of potential modifiers of storage-sugar concentration contributed by $\mathrm{P}_{2}$. For future reference and consistent with current rules for nomenclature in tomato genetics (Clayberg et al., 1970, 1973), we propose that the major gene regulating the percentage of reducing sugar in tomatoes be designated sucr.

In addition to differences in the percentage of reducing sugar in the parental lines, large differences in the glucose : fructose $(\mathrm{G}: \mathrm{F})$ ratios were also evident. $G: F$ ratios of 0.06 and 0.90 were observed in fruit of L. hirsutum $\left(\mathrm{P}_{2}\right)$ and L. esculentum $\left(\mathrm{P}_{1}\right)$, respectively (Table 1). Slightly higher amounts of fructose than glucose are typical of ripe $L$. esculentum fruit and normally result in $\mathrm{G}: \mathrm{F}$ ratios of 0.8 to 1.0 (Davies, 1966). In fruit of sucrose-containing wild species, however, glucose concentrations are commonly low relative to those of fructose and result in much lower $G: F$ ratios than those typically noted in L. esculentum. The influence of the

Table 1. Sugar concentrations in tomato populations derived from an initial cross of $L$. esculentum 'Floradade' and $L$. hirsutum f. typicum PI 390514.

\begin{tabular}{|c|c|c|c|c|c|c|}
\hline \multirow[b]{2}{*}{ Population $^{z}$} & \multirow{2}{*}{$\begin{array}{c}\text { No. } \\
\text { of } \\
\text { individuals }\end{array}$} & \multicolumn{3}{|c|}{$\begin{array}{l}\text { Sugar concn }(\text { mean } \pm S E) \\
\left(m g \cdot g{ }^{1} \text { fresh wt }\right)\end{array}$} & \multirow{2}{*}{$\begin{array}{l}\text { Reducing } \\
\text { sugar } \\
\text { (\% of total) }\end{array}$} & \multirow{2}{*}{$\begin{array}{c}\text { Glucose : } \\
\text { fructose } \\
\text { ratio }\end{array}$} \\
\hline & & Fructose & Glucose & Sucrose & & \\
\hline$\overline{P_{1}}$ & 6 & $14.0 \pm 1.3$ & $12.5 \pm 1.2$ & $0 \pm 0$ & $100 \pm 0$ & $0.90 \pm 0.03$ \\
\hline$P_{2}$ & 20 & $4.0 \pm 0.3$ & $0.3 \pm 0.2$ & $31.7 \pm 2.6$ & $13.4 \pm 1.7$ & $0.06 \pm 0.03$ \\
\hline $\mathrm{F}_{1}$ & 20 & $27.0 \pm 1.2$ & $10.2 \pm 0.5$ & $0 \pm 0$ & $100 \pm 0$ & $0.38 \pm 0.01$ \\
\hline $\mathrm{F}_{2}$ & 174 & $16.9 \pm 0.7$ & $7.5 \pm 0.5$ & $7.1 \pm 0.9$ & $79.1 \pm 2.4$ & $0.40 \pm 0.01$ \\
\hline $\mathrm{BC}_{1}$ & 93 & $18.8 \pm 0.8$ & $14.1 \pm 0.7$ & $1.2 \pm 0.5$ & $97.4 \pm 0.8$ & $0.73 \pm 0.02$ \\
\hline
\end{tabular}

${ }^{\mathrm{z}} \mathrm{P}_{1}=$ L. esculentum 'Floradadc'; $\mathrm{P}_{2}=L$. hirsutum $\mathrm{f}$. typicum $\mathrm{PI} 390514 ; \mathrm{BC}_{1}=$ backeross; $\mathrm{P}_{1}$ was used as the recurrent parent in the $\mathrm{BC}_{1}$ generation. 


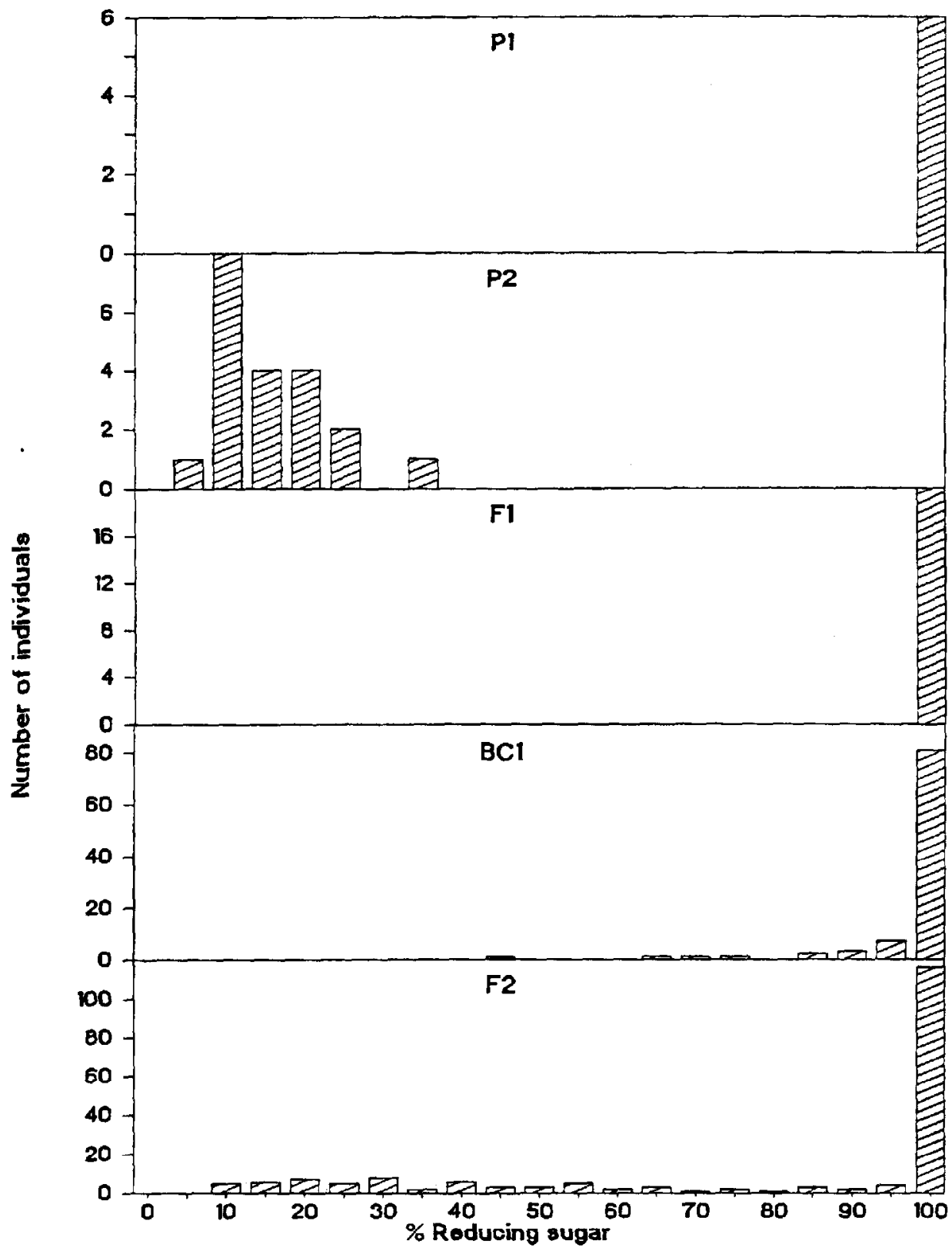

Fig. 1. Percentage of reducing-sugar concentration of plants from one parent $\left(\mathrm{P}_{1}=\right.$ Lycopersicon esculentum 'Floradade') with a high and one ( $\mathrm{P}_{2}=L$. hirsutum f. typicum PI 390514) with a low percentage of reducing sugar and progeny of $F_{1}, F_{2}$, and backcross $\left(B C_{1}\right)$ generations. Scales on the ordinate are dissimilar.

parental phenotypes $\left(\mathrm{P}_{1}\right.$ and $\mathrm{P}_{2}$ on fruit $\mathrm{G}: \mathrm{F}$ ratios was evident in $\mathrm{F}_{1}, \mathrm{~F}_{2}$, and $\mathrm{BC}_{1}$ progeny, a result suggesting a genetic basis for glucose and fructose concentrations. Hayman's generational means analysis revealed that additive effects $(\mathrm{a}=0.47, \mathrm{SE}=0.06)$ were important for $\mathrm{G}: \mathrm{F}$ ratios but that dominance effects were not $[\mathrm{d}=$ $(-0.11)$. SE $=0.071$. A relationship between fruit $\mathrm{G}: \mathrm{F}$ ratios and storage-sugar type was not evident since sucrose was not detectable in $F_{1}$ or $B_{1}$ fruit (Table 1). These results suggest that $G: F$ ratio and percentage of reducing sugar are under separate genetic control. Thirteen of $174(\approx 1 / 13) \mathrm{F}_{1}$ plants were noted with a $\mathrm{G}: \mathrm{F}$ ratio of 0.85 to $1.02\left(\mathrm{G}: \mathrm{F}\right.$ range for $\left.\mathrm{P}_{1}\right)$. An equal number of $\mathrm{F}_{2}$ plants was observed with a $G: F$ ratio of 0 to 0.37 , a result consistent with the $G$ : F ratio observed in $P$,. The observed segregation patterns for parental extremes within this $F_{2}$ population suggests that the $G: F$ ratio in tomato is controlled by at least two genes (Rothwell, 1979; Sinnott et al., 1950).

Considerable variation for fruit TSS and sugar concentration
Table 2. Chi-square analysis of percentage of reducing sugar in tomato parental $\left(\mathrm{P}_{1}\right.$ and $\left.\mathrm{P}_{2}\right), \mathrm{F}_{1}, \mathrm{~F}_{2}$, and backcross $\left(\mathrm{BC}_{1}\right)$ populations.

\begin{tabular}{lrrrrr}
\hline & \multicolumn{2}{c}{ Reducing sugar ${ }^{z}(\%)$} & Ratio & Chi- \\
\cline { 2 - 4 } Population $^{\mathrm{y}}$ & High & Low & Total & tested & square \\
\hline $\mathrm{P}_{1}$ & 6 & 0 & 6 & $1: 0$ & 0 \\
$\mathrm{P}_{2}$ & 0 & 20 & 20 & $0: 1$ & 0 \\
$\mathrm{~F}_{1}$ & 20 & 0 & 20 & $1: 0$ & 0 \\
$\mathrm{~F}_{2}$ & 139 & 35 & 174 & $3: 1$ & $2.3^{\mathrm{x}}$ \\
$\mathrm{BC}_{1}$ & 93 & 0 & 93 & $1: 0$ & 0
\end{tabular}

${ }^{\mathrm{z}}$ Fruit of respective progeny were classified as containing a high $(>37 \%)$ or low $(<37 \%)$ percentage of reducing sugar based on the percentage of reducing sugar in parental lines.

${ }^{\text {}} \mathrm{P}_{1}=$ Lycopersicon esculentum 'Floradade'; $\mathrm{P}_{2}=$ L. hirsutum f. typicum $\mathrm{PI} 390514 ; \mathrm{P}_{1}$ was used as the recurrent parent in the $\mathrm{BC}_{1}$ generation. ${ }^{x} P>0.1$; probability values $>0.05$ suggest that observed values do not differ significantly from the expected values. 
Table 3. Total sugar and soluble solids concentrations in parental $\left(\mathrm{P}_{1}\right.$ and $\left.\mathrm{P}_{2}\right), \mathrm{F}_{1}, \mathrm{~F}_{2}$, and backcross $\left(\mathrm{BC}_{1}\right)$ populations.

\begin{tabular}{lcc}
\hline & \multicolumn{2}{c}{ Concn [mean \pm SE (range)] } \\
\cline { 2 - 3 } & \multicolumn{2}{c}{ Total soluble } \\
solids & $(\%)$ & $\begin{array}{c}\text { Total sugar } \\
\left(\mathrm{mg} \cdot \mathrm{g}^{-1} \text { fresh wt) }\right.\end{array}$ \\
Population $^{2}$ & $5.6 \pm 0.2(4.7-6.2)$ & $26.5 \pm 2.5(16.2-34.9)$ \\
$\mathrm{P}_{1}$ & $7.5 \pm 0.3(5.3-10.4)$ & $36.0 \pm 2.6(17.4-60.3)$ \\
$\mathrm{P}_{2}$ & $6.9 \pm 0.2(5.2-8.3)$ & $37.2 \pm 1.7(24.6-54.5)$ \\
$\mathrm{F}_{1}$ & $6.5 \pm 0.1(4.0-12.9)$ & $31.5 \pm 1.0(5.7-73.0)$ \\
$\mathrm{F}_{2}$ & $6.6 \pm 0.2(3.3-11.9)$ & $34.1 \pm 1.5(3.9-70.3)$ \\
$\mathrm{BC}_{1}$ &
\end{tabular}

${ }^{\mathrm{Z}} \mathrm{P}_{1}=$ Lycopersicon esculentum 'Floradade'; $\mathrm{P}_{2}=$ L. hirsutum $\mathrm{f}$. typicum PI 390514; $\mathrm{BC}_{1}=$ backcross; $\mathrm{P}_{1}$ was used as the recurrent parent in the $\mathrm{BC}_{1}$ generation.

was observed within the populations developed (Table 3). Lycopersicon hirsutum PI 390514 is higher in total sugar and TSS concentration relative to the $L$. esculentum cultivar used in this study, yet lower in TSS and sugar concentration compared to many other L. hirsutum accessions (J. Stommel, unpublished data). Despite this fact, sugar and TSS concentration in fruit of parental, $\mathrm{F}_{1}, \mathrm{~F}_{2}$, and $\mathrm{BC}_{1}$ generations indicated a positive effect of the $L$. hirsutum parent $\left(\mathrm{P}_{2}\right)$ on total sugar and TSS concentration in $\mathrm{F}_{1}$ progeny and subsequent generations. $\mathrm{F}_{2}$ and $\mathrm{BC}_{1}$ progeny with TSS and total sugar concentrations equal to or greater than those observed in the high-TSS L. hirsutum parent were noted. Relative to $\mathrm{P}_{1}$, overall increases in total sugar and TSS concentration of $28 \%$ and $18 \%$, respectively, were realized in the $\mathrm{BC}_{1}$ generation, a result suggesting that improved breeding lines can be developed using this and other L. hirsutum accessions as high-TSS donor parents.

Previous studies have focused on the potential for increasing TSS in tomato by incorporating sucrose accumulation from wild tomato species into cultivated types that store predominantly reducing sugars (Stommel, 1992; Yelle et al., 1988, 1991). The results of the current study suggest that factors in addition to the storage of sucrose, as opposed to reducing sugars, positively influence TSS concentration. $\mathrm{F}_{1}$ and $\mathrm{BC}_{1}$ progeny contained higher concentrations of TSS and total sugar relative to the L. esculentum parent $\left(\mathrm{P}_{1}\right)$, yet stored free sugars as glucose and fructose (Tables 1 and 3). Thus, the higher TSS and total sugar concentration in these progeny may be conditioned by a positive effect of the $L$. hirsutum parent on TSS and total sugar concentration, irrespective of storage-sugar type; elevated concentrations of additional components including organic acids or water-soluble polysaccharides, which influence TSS concentration; or both.

The benefits to be realized in increasing tomato sugar concentration are substantial for processed and fresh tomato markets. Increases in total sugar concentration are correlated with increased TSS concentrations in tomato, thus reducing the energy inputs required to produce processed tomato products. Current estimates indicate that a $1 \%$ increase in tomato TSS concentration could be worth $\$ 70$ million to $\$ 80$ million a year to the tomato processing industry (Wood, 1992). A negative relationship between TSS and yield, however, has limited past efforts to increase TSS (Stevens and Rudich, 1978). The relationship between yield and increased TSS concentrations conditioned by sucrose accumulation has not been determined in advanced populations derived from $L$. esculentum $\times$ L. hirsutum crosses. Since sugars, together with acids, are also the principal flavor components of tomatoes (DeBruyn et al., 1971; Stevens et al., 1977), an increase in total sugar concentration will also enhance tomato flavor. Flavor and market quality of fresh tomatoes have been the subject of substantial criticism recently (Sokolov, 1989). Although the relative perceived sweetness is fructose > sucrose > glucose (Shallenberger and Birch, 1975), the overall increase in total sugar concentration likely would negate any net loss in sweetness due to decreased fructose concentrations.

In summary, this report provides evidence indicating that the regulation of sugar type in tomato is controlled by a simply inherited major gene, designated sucr, dominant for a high percentage of reducing sugar. The $G: F$ ratio in these populations seems to be under separate genetic control and is influenced by at least two pairs of alleles. High TSS and sugar concentrations in tomato populations with a high percentage of reducing sugar suggests that components in addition to sucrose accumulation contribute to the high TSS concentrations conditioned by $L$. hirsutum accessions. In considering the simply inherited nature of sugar type in tomatoes, the potential benefits to be realized in fruit of new tomato cultivars that store sugars as sucrose may have practical applications in improving tomato quality components.

\section{Literature Cited}

Clayberg, C.D., L. Butler, E.A. Kerr, C.M. Rick, and R.W. Robinson. 1970. Rules for nomenclature in tomato genetics. Rpt. Tomato Genet. Coop. 20:3-5.

Clayberg, C.D., L. Butler, E.A. Kerr, C.M. Rick, and R.W. Robinson. 1973. Additional rules for nomenclature. Rpt. Tomato Genet. Coop. 23:3.

Davies, J.N. 1966. Occurrence of sucrose in the fruit of some species of Lycopersicon. Nature 209:640-641.

Davies, J.N. and R.J. Kempton. 1975. Changes in the individual sugars of tomato fruit during ripening. J. Sci. Food Agr. 26: 1103-1110.

DeBruyn, J.W., F. Garretsen, and L. Kooistra. 1971. Variation in taste and chemical composition of the tomato (Lycopersicon esculentum Mill.). Euphytica 20:214-227.

Freeman, R.E. and P.W. Simon. 1983. Evidence for simple genetic control of sugar type in carrot (Daucus carota L.). J. Amer. Soc. Hort. Sci. 108:50-54.

Giaquinta, R.T. 1979. Sucrose translocation and storage in the sugar beet. Plant Physiol. 63:828-832.

Hatch, M.D., J.A. Sacher, and K.T. Glasziou. 1963. Sugar accumulation cycle in sugar cane. II. Relationship of invertase activity to sugar content and growth rate in storage tissues of plants grown under controlled environments. Plant Physiol. 38:344-348.

Hayman, B.I. 1958. The separation of epistatic from additive and dominance variation in generation means. I. Heredity 12:371-390.

Hayman, B.I. 1960. The separation of epistatic from additive and dominance variation in generation means. II. Genetica 31:133-146.

Hewitt, J.D., M. Dinar, and M.A. Stevens. 1982. Sink strength of fruits of two tomato genotypes differing in total fruit solids content. J. Amer. Soc. Hort. Sci. 107:896-900.

Hewitt, J.D. and T.C. Garvey. 1987. Wild sources of high soluble solids in tomato, p. 45-54. In: D.J. Nevins and R.A. Jones (eds.). Plant biology. vol. 4. Tomato biotechnology. A.R. Liss, New York.

Ho, L.C. 1979. Regulation of assimilate translocation between leaves and fruits in the tomato. Ann. Bot. 43:437-448.

Hubbard, N.L., S.C. Huber, and D.M. Pharr. 1989. Sucrose phosphate synthase and acid invertase as determinants of sucrose concentration in developing muskmelon (Cucumis melo L.) fruits. Plant Physiol. 91:15271534.

Miron, D. and A.A. Schaffer. 1991. Sucrose phosphate synthase, sucrose synthase, and invertase activities in developing fruit of Lycopersicon hirsutum Humb. and Bonpl. Plant Physiol. 95:623-627.

Moriguchi, T., K. Abe, T. Sanada, and S. Yamaki. 1992. Levels and role of sucrose synthase, sucrose phosphate synthase, and acid invertase in sucrose accumulation in fruit of Asian pear. J. Amer. Soc. Hort. Sci. 117:274-278.

Rothwell, N.V. 1979. Understanding genetics. 2nd ed. Oxford Univ. Press. New York. 
Shallenberger, R.S. and G.G. Birch. 1975. Sugar chemistry. A VI Publishing, Westport, Conn.

Sinnott, E.W., L.C. Dunn, and T.H. Dobzhansky. 1950. Principles of genetics. 4th ed. McGraw Hill, New York.

Sokolov, R. 1989. Square, gassed tomatoes and other modem myths. Natural History 97(7):70-72.

Steingrover, E. 1983. Storage of osmotically active compounds in the taproot of Daucus carota L. J. Expt. Bot. 34:425-433.

Stevens, M.A., A.A. Kader, M. Albright-Holton, and M. Algazi. 1977. Genotypic variation for flavor and composition in fresh market tomatoes. J. Amer. Soc. Hort. Sci. 102:680-689.

Stevens, M.A. and J. Rudich. 1978. Genetic potential for overcoming physiological limitations on adaptability, yield and quality in the to- mato. HortScience 13:673-678.

Stommel, J.R. 1992. Enzymatic components of sucrose accumulation in the wild tomato species Lycopersicon peruvianum. Plant Physiol. 99:324-328.

Stommel, J.R. and P.W. Simon. 1989. Phenotypic recurrent selection and heritability estimates for total dissolved solids and sugar type in carrot. J. Amer. Soc. Hort. Sci. 114695-699.

Wood, M. 1992. Solid future for tomatoes. Agr. Res. 40(3):4-5.

Yelle, S., R.T. Chetelat, M. Dorais, J.W. DeVerna, and A.B. Bennett. 1991. Sink metabolism in tomato fruit. IV. Genetic and biochemical analysis of sucrose accumulation. Plant Physiol. 95:1026-1035.

Yelle, S., J.D. Hewitt, N.L. Robinson, S. Damon, and A.B. Bennett. 1988. Sink metabolism in tomato fruit. III. Analysis of carbohydrate assimilation in a wild species. Plant Physiol. 87:737-740. 